\title{
The Impact of Forests in Climate Change
}

\author{
Sevim Inanç*, Hüseyin Ayaz \\ *Department of Forest Engineering, Artvin Çoruh University, Artvin, Turkey
}

\begin{abstract}
As parallel to industrialization and increasing population, pressures on natural resources have rised, soil, water and air have been polluted. These problems threaten the human. So, environmental protection or in awider meaning nature conservation became a very important duty for the human in this century. The duty is aspecial action against eradication of living base for the organisms Forest ecosystems are of course economicalnatural resources. The ecosystem is a monotonous forest area by compositions, characteristics andrelationsihips of the main elements within the forest. In the article, firstly, forest ecosystems and their functionswere examined, then, importance of forest as natural resources, their roles for preventing risk of climaticalchanges, and contribution of forests for sustainable development within Turkiye were studied.
\end{abstract}

Keywords - Climate change, Forest resource, Forest Ecosystems.

\section{INTRODUCTION}

At the beginning of the environmental problems threatening the world in recent years is the problem of "global warming and climate change". The importance of global warming and climate change, economic, ecological and sociological problems that are effective in almost every part of the world is increasing and it is noteworthy.

Since global issues can only be solved by global cooperation, the Framework Convention on Climate Change, which was adopted in 1992 at the Rio de Jenario Environment and Development Conference and entered into force on 21 March 1994. This contract was strengthened by the Kyoto Protocol in 1997.

The region in which Turkey is located faces water shortages, drought and soil erosion problems, Turkey places the harmful and violent effects of global warming among the countries that will live first. In this respect, Turkey participated as the 189th party to the Framework Convention on Climate Change as of 24 May 2004. Turkey's per capita responsibility for producing carbon dioxide emissions, which cause global warming, is less than in other OECD and European Union countries. However, since 1980, Turkey's energy-related gas emissions have increased and can be avoided, necessitating the change of existing technology. In order to control energy-related environmental problems in the name of sustainable development and to minimize the negative environmental impacts of energy activities, Turkey should set energy-related policies well and set targets closer to "renewable energy" in particular

"Global warming and climate change" emerged as a result of industrialization, energy production, the destruction of forests and other human activities, especially in the use of fossil fuels, is one of the biggest environmental problems that threaten the world. This problem is growing more and more with economic growth and population growth. Global warming is the process of artificially raising the temperature of the earth's atmosphere with the atmospheric layers near the earth as a result of the intensive increase of the greenhouse gases in the atmosphere as a result of various activities of the people. Global climate change is a change in other climate elements (precipitation, humidity, air movement, drought, etc.) due to global warming.

It has been estimated that human beings have not undergone very large changes in the world climate and temperatures. However, the findings of climatologists show that this situation does not remain the same throughout the history of the world, and that the world climate system is far from being a stagnant structure. Cold periods that last for tens of millions of years after warm periods that last for hundreds of millions of years, warmths that last ten thousand years in these periods, and relatively light, cold, hot periods that last for tens or hundreds of years.

According to some scientists, in the past 250 thousand years, the world was warming 1 degree. According to recent researches, the climate of the world, which should be in the cooling period nowadays, is not a cold turn; on the contrary, it shows that it has entered a hot round to the extent of danger. According to some researches, the world has warmed up to 1 degree from 1850 to 2000, while some other studies have shown that mean global temperature increases from 0.5 to $0.8^{\circ} \mathrm{C}$ from 1860 to sun. It is stated that the Industrial Revolution, which started in the year 1790, had a great effect. Dangerous aspect of this situation is that the speed of heating is doubled. Since 1979, the temperature has increased by 0.12 degrees every 10 years. The Intergovernmental Panel on Climate Change (IPCC), established by the UN, with over 150 countries, shows some evidence that climate change is alive now (Godrej, 2003).

The main reasons for global warming and climate change in the world are listed as follows:

World Movements: In the 1930's, the elliptical orbital orbits around the Sun's Earth have been proven by 
scientists who have been extruded every 95,000 years. This period brings to mind a hundred thousand years of ice age.

Earth Movements: Some climatologists suggest that continental drifts, mountain occurrences, changes in the magnetic field of the Sun, and sunspots may have an impact on climate change.

Increase in Greenhouse Gas Emissions: The most important cause of global warming is the atmospheric release of greenhouse gases. In particular, the increase of carbon dioxide $(\mathrm{CO} 2)$ and methane $(\mathrm{CH} 4)$ gases in the atmosphere increases the temperature of the earth's surface (CNN Türk, 2007).

Greenhouse gases inhibit the energy balance of the planet and cause the surface temperature to rise, preventing the infrared radiation reflected from the earth's surface from escaping to the far side. This effect of greenhouse gases is called "greenhouse effect of the atmosphere", which is called "global warming under the influence of greenhouse gases"

Other Reasons: The most important changes human beings make on earth with their own hands, apart from greenhouse gas emissions, are the rapid expansion of agricultural areas, the rapid destruction of forested areas, the desertification of semi-arid areas and the urbanization

For example, while the reduction of forest areas increases the amount of carbon dioxide and thus the greenhouse effect, desertification slows down global warming by reducing solar heat by increasing the amount of dust in the atmosphere. Urbanization is important not only because of the direct impact of global climates, but also because it creates heat islands that are warmer than their surroundings.

\section{GLOBAL WARMING AND EFFECTS OF CLIMATE CHANGE}

The effect of greenhouse gases on the emergence of earth's climate and climate has undeniable precaution. Greenhouse gases, by keeping some of the sun's rays reflected from the earth, allow the earth to stay at a temperature that people and other living things can live. If there were no greenhouse gases in the atmosphere, it is estimated that the average temperature of the earth would be $33{ }^{\circ} \mathrm{C}$ colder than the daylight. Particularly during the last 30 years, the effects of global warming have been increasing, mainly due to technological developments, increased fuel consumption and population

growth, increased emissions of atmospheric greenhouse gases, and ozone depletion. Global warming is not just a phenomenon of increasing temperatures in every part of the world. According to the scientists; global warming will lead to extreme temperatures and fires in another region, while intense drought in a certain region of the world, and in another region, severe tornados and storms following the storms. The sea level rise will be seen. Along with the change of ecosystems, biodiversity will face the danger of extinction. As a result of global problems in the production of food, more poverty and illness will emerge. As a result of global warming, high summer temperatures, forest fires, reduced rainfall and water resources, drought and desertification, and so on. it is inevitable that Turkey will be influenced by negative changes as well as some countries.

Especially since the second half of the 20th century, natural disasters threatening the life of plants and animal species, especially humans, have begun to emerge with the rapid increase of greenhouse gases In other researches carried out on the same subject, the effect of human energy use on global warming was found to be highest (Kadığlu, 2007)

Sudden and unstable climatic conditions may make it impossible to find food because it can cause erosion, landslides, flood disasters, forest fires and desertification in arable areas, leading to the rapid disappearance of agricultural areas. Since the burning of forests, desertification, erosion events will cause more greenhouse gases such as $\mathrm{CO} 2$ to be released into the atmosphere, the effects of global warming will begin to be less visible.

\section{CLIMATE CHANGE AND FORESTS}

There is a two-way relationship between climate change and forest ecosystem. On the one hand, forests, ecosystems, lands, trees, trees and herbaceous plants; carbon dioxide in the atmosphere. In this regard, they play an important role in combating climate change by creating important carbon sink areas. On the other hand, however, during the forest fires is the release of organic carbon in the forests, forest soil and dead and alive cover to the atmosphere. In this way, if forests are not properly protected, they can play a role in accelerating climate change.

On a global scale, forest ecosystems hold about 3 billion tons of carbon dioxide released every year as a result of human activities. This means $35 \%$ of $\mathrm{CO} 2$ emissions from fossil fuels when calculated based on 2007 base of Carbon Dioxide Information Analysis Center. There is no less costly way to prevent deforestation to reduce 1 ton of carbon dioxide emissions. Therefore, it is of great importance to protect forest areas and to increase carbon capture capacity of forests to combat climate change (OGM; 2011).

Forests also play an active role in adaptation, reducing the impact of climate change. For example, forest ecosystems can mitigate the effects of climate change by reducing the effects of floods and erosion, and in the case of reduced agricultural production due to drought, they can benefit as additional income for the people of the region through forest fuels (OGM, 2011). 
On the other hand forest ecosystems, are sensitive areas. Forest fires are expected to be more frequent and more intense in forest ecosystems, especially due to climate change, due to increased disease and harmfulness in the trees and high temperature and hot weather fluctuations (IPCC, 2007). Each year, on average $1 \%$ of world forest areas are burned with various causes. The fires cause both the destruction of forests, which are important carbon sink sites, and the release of organic carbon held in these sinks into the atmosphere as carbon dioxide during combustion. Therefore, forests play a crucial role in combating climate change in their right corridors, and they accelerate climate change if they are misused.

In this respect, forests should be less influenced by climate change, methods should be defined to help forest ecosystems to adapt to the inevitable effects of climate change, and strategies should be developed on the rational use of forests to combat climate change.

Tropical forests are the largest carbon deposits on Earth. $80 \%$ of the total carbon stock is in the tropical forests. Tropical forests are temperate zone with $\%$ i7, boreal with $3 \%$ (forest zone follows cold) (BROWN 1997).

According to the evaluations made in the 1980s, it is reported that all the forests in the earth have stored $830 \mathrm{Pg}$ carbon (petagram $=1015 \mathrm{~g}=1$ gigaton $=1$ billion tons) in total and that the amount stored in the soil is 1.5 times more than the storage in the vegetation (Brown, 1997). In this total budget, young temperate and boreal forests serve as a net repository, while tropical forests, which are constantly destroyed, emerge as a clear $\mathrm{CO} 2$ source (emissions). Globally, forests are a clear source of carbon, and the reasons for this include deforestation, particularly in tropical regions. However, proper management of forests will ensure that the clear $\mathrm{CO} 2$ emissions from the forests are stopped and serve as a clear repository. In this way, $11-15 \%$ of fossil fuel emissions can be stored in CO2 forests (Brown, 1997). Globally meaning forests with quantities of $\mathrm{C}$ stored in terrestrial ecosystems It is estimated that in 2005, 572 billion tons of stems (280 billion tons of Carbon equivalent) were carried; $33 \%$ in South America, 21\% in Africa, $11 \%$ in Asia and $4 \%$ in Oceania. In 2005, it is estimated that the total forest carbon is 633 billion tons, which is equivalent to 160 tons of carbon per hectare. The total carbon in the forest biomass in Europe is $16 \%$ of the global total, while the carbon in the earth in Europe is more than $40 \%$ of the global total. Greenhouse gas emission rate (especially $\mathrm{CO} 2$ ) is calculated on the basis of biomass loss based on land use change and deforestation estimates. Globally, the rate of decline of forest carbon is estimated to be 1.6 billion tons per year, with $0.25 \%$ of total forest carbon. Tropical forests have an important influence both on input and output in global carbon budget. For example, forest vegetation in the Amazon region has 70 billion tonnes of carbon deposits, and deforestation between 1970 and 1998 resulted in atmospheric release of approximately 7 billion tonnes of carbon dioxide, equivalent to an average of 0.4 billion tonnes of carbon per year. Despite the uncertainties in estimating forest-related carbon emissions, there is no doubt about the significant role of forests in carbon sequestration and forest-wide emissions to the global carbon cycle.

This issue is discussed under specific headings during the international climate negotiations process, due to the special importance of climate change and fighting forests. The concept of REDD has been on the agenda for the first time in 2005, reducing the emissions from deforestation and deforestation in developing countries and protecting forests, the role of sustainable management of forests and increasing forest carbon stocks. Especially in developing countries with significant forest reserves of the world, such as rain forests, the importance of reducing greenhouse gas emissions resulting from deforestation and degradation of forests and protecting forests is emerging.

\section{CLIMATE CHANGE AND TURKISH FORESTS}

In the 2007 IPCC Intergovernmental Panel on Climate Change (IPCC), it is stated that climate change, which includes Turkey, may destroy forest ecosystems due to climate change and thus may lead to socio-economic changes (OGM, 2011). Climate change is shown in scientific studies which will increase forest fires and treedamaging insect population in Turkey and thereby increase deforestation (OGM, 2011).

The 12 million hectares of forests in Turkey correspond to approximately $60 \%$ of the forest area is located in the sensitive Mediterranean climate zone.

In addition to forest fires, harmful insects and diseases also damage forest areas due to the increase in temperature. Due to these insects that damage forests, the ability, quality and quantity of regeneration of forests is decreasing. Approximately 2 million hectares of pests (insects, fungi, etc.) are affected in the forest area every year in Turkey, causing an average of 1 million $\mathrm{m} 3$ of wood product loss (OGM, 2011).

With 78 million hectares of land, Turkey has a rich diversity in ecological care. In this richness, forests also play an important role as species and composition. According to the estimations made by the year 2015, forest areas occupy $28.6 \%$ of the country area. Trees without forests are not included in these areas.

With the Five-Year Development Plans, the forest inventory was started in 1963, and the forest inventory records of the whole country were made in 1980 and the forest inventory data obtained in 1980 was published. 
According to the inventory evaluation results of this period; the overall forest area was 20.2 million hectares, the total tree wealth was 935 million $\mathrm{m} 3$, and the annual current increase was 28 million m3. An annual average of 23 million $\mathrm{m} 3$ of this increase is planned as a benefit for wood production. So; 5 million $\mathrm{m} 3$ increase every year, left in the forest for wealth accumulation (OGM, 2006).

After 1973, the information in the renewed plans was updated and the amount of forest area of the country in 1999 was determined as 20.8 million hectares. The forest area, which reached 21.2 million hectares in 2004, constituted $27.2 \%$ of the country's general area. The forest area, which was determined as 21.7 million hectares between the years 2005-2012, reached $27.7 \%$ of the country's general area and 22.3 million hectares between 2013 and 2015 , reaching $28.6 \%$ of the country's total area The various effects of forest ecosystem on the climate are listed as follows: Forests increase rainfall. Considering the forested and non-forested areas with the same conditions, according to the results of the research done in the former Soviet Union; the amount of rainfall in the forested area was found to be $50 \%$ higher than the forested steppe zone (Anonim, 1998 and Dağdaş, 2003). The forests increase the air humidity! For example, an oak tree raises the air humidity by an average of 570 liters of water per day, with an average of 20 tons of water per year roots of water per year, giving atmospheres to the atmosphere (Anonim, 1998). As the relative humidity of air increases, the vaporization power of the atmosphere decreases. For example, when the relative humidity is $20 \%$, the evaporation power is 2000 bar, the relative humidity is $70 \%$, and the evaporation power is 500 bar. In this respect, the water economy of the growing environment remains dormant and moist (Dağdaş, 2003).

The forests cleans the air we breathe! The findings of a research carried out are as follows: One hectare pine forest cleans and cleans 30 to 40 tons of spruce, 32 tons of spruce forest and 68 tons of beech forest (Anonim, 1998). The beech tree strains out, absorbing $700 \mathrm{Kg}$ of dust and 300 $\mathrm{Kg}$ of venom in a year. Excessive contamination will alarm with deterioration of the torso. City forests like natural forests also prevent air pollution! Swallow the dust! Cleans the air! The results reached in the findings of a research are as follows: $420-850$ in the city center of Hamburg. The amount of dust in $\mathrm{mgr} / \mathrm{m}^{3}$ was measured as $100 \mathrm{mgr} / \mathrm{m}^{3}$ in the city park. Forest air contains $90-99 \%$ less tonnes of air in the city (Anonim, 1998). In another research, one liter of trees in the air without trees; 3-4 times more than trees and 10 times more dust than parks (Ürgenç, 1990).

Forests also compensate for temperature changes! A coniferous forest absorbs most of the solar energy from the "roof top" (1.3 $\left.\mathrm{g} \mathrm{Kal} / \mathrm{cm}^{2} / \mathrm{min}\right) .61 \%$ of these are given again as atmospheres (Çepel, 1983 and Dağdaş, 2003). From here it can be predicted what the negative temperature effect will be when the forest cover is raised from the center. The

It has been determined that the fatty acid content of tea seeds of Artvin region is similar to the seeds grown in different countries in the literature. In the study, tea seed oil was compared with sunflower oil and linoleic acid content was found to be lower. This feature increases the stability of cooking oil.As a result, the tea seed oil from Artvin Turkey was defined as high quality cooking oil, like olive oil.

In addition, the composition of the outer and inner shell of tea seeds was also determined. These results indicate that these waste products are a serious holocellulose $(62.1 \%)$ source. Mixture of outer and inner shell is including $33.1 \%$ and $41.4 \% \alpha$-cellulose and lignin respectively. Tea seed shells can be utilized at pyrolysis, alcohol production, fibreboard production and wood plastic composite production like wood and annual plants.

\section{CONCLUSIONS AND SUGGESTIONS}

At the front line of environmental problems that threaten the world are "global warming and climate change" and the ecological transformations that accompany it. The release of greenhouse gases (especially $\mathrm{CO} 2, \mathrm{CH} 4$ and NOX), naturally found in the atmosphere and preventing our Earth from over cooling, has shown a post-human increase in activity. As natural backwashing processes are challenged, the density of greenhouse gases has constantly risen and, as a result, a process is beginning to take place, with the average temperature rising on the surface of the earth. Since the mid-1990s, global warming and climate change have become an irrefutable fact of mankind

The forests that make up an important ecosystem of our country are climate sensitive. Because; Forests Prevent overheating of the atmosphere as it absorbs most of the short-wave solar radiation from the sun itself. It contributes significantly to the formation of rainfall. It also absorbs $\mathrm{CO} 2$ and produces Oxygen. It forms a strong micro-airconditioning area between the bottom of the leaves and the ground. It provides the protection of soil and bottom creatures against direct solar radiation, which is effective during the day, and adverse effects caused by extreme colds during nights and cold winter days (Kayhan, 2006).

Depending on the effects of climate change, degradation and shrinkage of forest areas is extremely important for our country. In particular, strategies and plans for adaptation of forests in Turkey to climate change need to be urgently developed when it is considered that $50 \%$ of Turkey's existing forest areas are degraded forests.

It is important to remember that forests play a key role in combating climate change with carbon sequestration, as well as by reducing the impact of climate change. From 
this point of view, methods should be developed to ensure that forest ecosystems are less affected first by climate change, methods to help forest ecosystems should be identified while adapting to the inevitable effects of climate change, and strategies should be developed on rational use of forests to combat climate change.

\section{REFERENCES}

[1] Anonim,(1998), Cumhuriyetimizin 75. Yllinda Ormancılı̆̆ımız, Orman Bakanlığı, Ankara.

[2] IPCC, 2007; 4th Assessment report, Forestry Chapter.

[3] BROWN, S. 1997: Forests And Climate Change: Role Of Forest Lands As Carbon Sinks. Proceedings of the XI World Forestry Congress Vol. 1pp. 117127.

[4] CNNTURK, 2007, "Global Warming Created by Man”,(http://www.cnnturk.com/science-technology /science/Global_warming/news_detail.asp?PID=160 0\&news.ID=295424, 07.05.2007).

[5] Çepel, N., (1983), Forest ecology, İ.Ü. Faculty of ForestPublications/No:3518/399, İstanbul.

[6] Dağdaş, S.,( 2003), A Bunch of Ecological Functions of Forests, Journal of Forestry and Economy, V:8, Ankara.

[7] GODREJ, D. (2003), Global Climate Change, Translated by OhannesKıllı̧dağı, 1st Printing, Metris Publications, İstanbul.

[8] KADIOĞLU, M. (2007), Global Climate Change and Turkey: As you know the last of the Air, 2.Edition, Current Publishing, İstanbul.

[9] Kayhan, M., (2006), Possible Effects of Global Climate Change and Turkey, ISU General Directorate of Cultural Publications N0:3, İzmit.

[10] OGM, 2011; General Directorate of Forestry, Climate Change and Forests, Ankara.

[11] Ürgenç, S., (1990), General Plantation and Afforestation Technique (Arborikulture), İ.Ü. Forestry Faculty Publications No:3512/393. İstanbul. 